\title{
Nutritional regulation of keratinolytic activity in Bacillus pumilis
}

\author{
Hong-Joo Son · Hyean-Cheal Park · Hong-Sung Kim •
}

Chung-Yeol Lee

Published online: 2 February 2008

(C) Springer Science+Business Media B.V. 2008

\section{Erratum to: Biotechnol Lett (2008) 30:461-465 \\ DOI 10.1007/s10529-007-9567-3}

The headings of the first two columns in both Table 1 and Table 2 were incorrect in the original publication. The corrected Tables 1 and 2 are shown on the following page.

The online version of the original article can be found under doi:10.1007/s10529-007-9567-3.

H.-J. Son $(\bowtie) \cdot$ H.-C. Park · H.-S. Kim

School of Applied Life Science, Pusan National

University, Miryang 627-706, Korea

e-mail:shjoo@pusan.ac.kr

C.-Y. Lee

School of Bioresource Science, Pusan National

University, Miryang 627-706, Korea 
Table 1 Specific activity of keratinolytic protease of Bacillus pumilis F3-4 in the presence of feather and different combinations of nutrients after 7 days

\begin{tabular}{|c|c|c|c|c|c|}
\hline Treatment & $\begin{array}{l}\text { Cell growth } \\
\left.\text { (c.f.u. } \times 10^{-9} / \mathrm{ml}\right)\end{array}$ & $\begin{array}{l}\text { Soluble protein } \\
(\mathrm{mg} / \mathrm{ml})\end{array}$ & $\begin{array}{l}\text { Specific activity } \\
\text { (U/mg) }\end{array}$ & $\begin{array}{l}\text { Keratin } \\
\text { degradation }(\%)\end{array}$ & $\begin{array}{l}\text { SH group } \\
(\mu \mathrm{M})\end{array}$ \\
\hline Feather & 5.6 & 1.2 & $11.9 \pm 0.9$ & $76 \pm 1.2$ & $2.41 \pm 0.07$ \\
\hline Feather + glucose & 19 & 1.4 & $14.6 \pm 0.8$ & $74 \pm 2.1$ & $2.34 \pm 0.03$ \\
\hline Feather $+\mathrm{NH}_{4} \mathrm{Cl}$ & 6 & 0.7 & $6.8 \pm 0.3$ & $48 \pm 3.1$ & $1.01 \pm 0.06$ \\
\hline Feather $+\mathrm{MgSO}_{4} \cdot 7 \mathrm{H}_{2} \mathrm{O}$ & 7.5 & 1.3 & $16.7 \pm 0.5$ & $80 \pm 1.2$ & $2.67 \pm 0.04$ \\
\hline Feather + glucose $+\mathrm{NH}_{4} \mathrm{Cl}$ & 6.4 & 0.5 & $7.8 \pm 0.5$ & $48 \pm 3.5$ & $0.81 \pm 0.06$ \\
\hline Feather + glucose $++\mathrm{MgSO}_{4} \cdot 7 \mathrm{H}_{2} \mathrm{O}$ & 6.7 & 1.6 & $18.8 \pm 0.3$ & $82 \pm 1.0$ & $2.62 \pm 0.02$ \\
\hline Feather $+\mathrm{NH}_{4} \mathrm{Cl}++\mathrm{MgSO}_{4} \cdot 7 \mathrm{H}_{2} \mathrm{O}$ & 6.2 & 0.7 & $7.4 \pm 0.4$ & $52 \pm 1.5$ & $1.01 \pm 0.03$ \\
\hline $\begin{array}{l}\text { Feather }+ \text { glucose }+\mathrm{NH}_{4} \mathrm{Cl}+\mathrm{MgSO}_{4} \\
\quad \cdot 7 \mathrm{H}_{2} \mathrm{O}\end{array}$ & 6.5 & 1.4 & $12.1 \pm 0.6$ & $77 \pm 1.5$ & $2.22 \pm 0.03$ \\
\hline Glucose $+\mathrm{NH}_{4} \mathrm{Cl}++\mathrm{MgSO}_{4} \cdot 7 \mathrm{H}_{2} \mathrm{O}$ & 9 & 0.8 & $9.4 \pm 0.4$ & - & - \\
\hline
\end{tabular}

Values are expressed as mean \pm SEM of three independent experiments

Table 2 Effect of keratinaceous substrates on specific activity of keratinolytic protease of Bacillus pumilis F3-4 after 7 days

Values are expressed as mean \pm SEM of three independent experiments

\begin{tabular}{lllll}
\hline Treatment & $\begin{array}{l}\text { Cell growth } \\
\left(\mathrm{c} . f . u . \times 10^{-9} / \mathrm{ml}\right)\end{array}$ & $\begin{array}{l}\text { Soluble protein } \\
(\mathrm{mg} / \mathrm{ml})\end{array}$ & $\begin{array}{l}\text { Specific activity } \\
(\mathrm{U} / \mathrm{mg})\end{array}$ & $\begin{array}{l}\text { Keratin } \\
\text { degradation }(\%)\end{array}$ \\
\hline Chicken feather & 5.6 & 1.2 & $11.2 \pm 0.4$ & $75 \pm 1.6$ \\
Duck feather & 6 & 1.5 & $8.8 \pm 0.3$ & $81 \pm 1.2$ \\
Feather meal & 10 & 1.8 & $17.5 \pm 0.2$ & $97 \pm 0.6$ \\
Human nail & 3.8 & 0.6 & $2.2 \pm 0.6$ & $15 \pm 1.5$ \\
Human hair & 4 & 0.4 & $8.4 \pm 0.2$ & $9 \pm 1.7$ \\
Sheep wool & 3.9 & 0.4 & $9.3 \pm 0.2$ & $10 \pm 1.5$ \\
\hline
\end{tabular}

